\title{
MOTIVAÇÃO NA PRODUÇÃO ESCRITA NA PERSPECTIVA DOS QUATRO DISCURSOS DE LACAN
}

\section{Ayrton Rodrigues Reis Orion Penna e Souza}

No início, o homem só tem de homem o status de animal vivo. Como tal, não passa de um ser de necessidades. Para conquistar sua identidade, será preciso que se torne ser de desejo, isto é, consciência desejante ou consciência de si. (DOR, 1989: 133).

\section{EM DIREÇÃO AO PROBLEMA}

Tendo como ponto de partida um impasse encontrado por uma estagiária do Curso de Letras da UFSM, ao tentar realizar uma tarefa com seus alunos, foi proposto pela mesma que os adolescentes criassem fanzines colocando neles o que quisessem, com enorme grau de liberdade de expressão como protestos, elogios, expectativas, informações curiosas, etc. Porém, a maioria dos alunos optou pela recusa à liberdade de escrita e preferiu silenciar, fazendo do papel um espaço risque-rabisque.

Que respostas a isso oferecem as teorias correntes que defendem a liberdade ao aluno de se expressar sobre aquilo que lhe é relevante e significativo, a fim de resgatar a motivação no ensino da escrita?

Diante desse entrave, Lacan nos apresenta caminhos de reflexão para as falhas atuais de transmissão no que se refere ao ato de educar. $O$ ato de educar propõe uma verdadeira transferência de trabalho. Então, que fenômenos estão aqui implicados? Propomo-nos, então, a examinar essa problemática na perspectiva da teoria dos quatro discursos de Lacan. Sob o ponto de vista dos quatro discursos, o autor nos fornece uma opção fértil de análise e entendimento das falhas da transmissão na relação pedagógica.

Como se sabe, a falência da transmissão na relação professor-aluno é um dos grandes problemas do ensino que aflige educadores e teóricos em Educação. De acordo com Mrech, (1997), professor e aluno se acham "imobilizados" por um imaginário que os impede de repensarem-se em seus respectivos papéis:

Os professores e alunos atuais vêm tecendo o seu "ser" simbólico através de determinadas informações, ou seja, daquilo que eles nomeiam "ser" professor e "ser" aluno. Entretanto, com isto ficam capturados no circuito das próprias representações estabelecidas, escapando de um processo de implicação ainda maior: as dificuldades do não-saber-fazer. (Mrech, 1997). 
A teoria da transferência de Lacan tem sem dúvida seu suporte teórico na diferença entre o imaginário e o simbólico. Na medida em que a transferência é sempre um fenômeno imaginário, o que o analista tem que fazer é quebrá-lo, transformar a relação imaginária em simbólica. (Etchegoyen, 1987: 78).

Segundo Mrech (1997), sabe-se que há atualmente no Brasil um sintoma que atinge os processos culturais de uma forma geral: a falência da transmissão na relação professor-aluno. Poderíamos pensar que, na verdade, através das colocações de Freud, estes processos não são novos, e revelam o que já se sabe: governar, psicanalisar e educar são profissões impossíveis. Mais claramente, não há A Educação, e sim uma (entre outras) educação, ou educações. Qual delas é a que convém? Quem saberá responder? No entanto, ainda de acordo com a autora, a situação que existia na época de Freud é bastante distinta daquela que se apresenta contemporaneamente. Antes, ainda se tentava ensinar, ou seja, atingir o aluno da época através de um contexto onde o saber recebia alguma forma de elaboração. Hoje, na rede pública brasileira, há uma descrença profunda em relação aos próprios processos de transmissão. O professor não acredita mais que ele possa ensinar; e os alunos por sua vez, que eles possam aprender. Os papéis do educador - educando se apresentam como uma farsa.

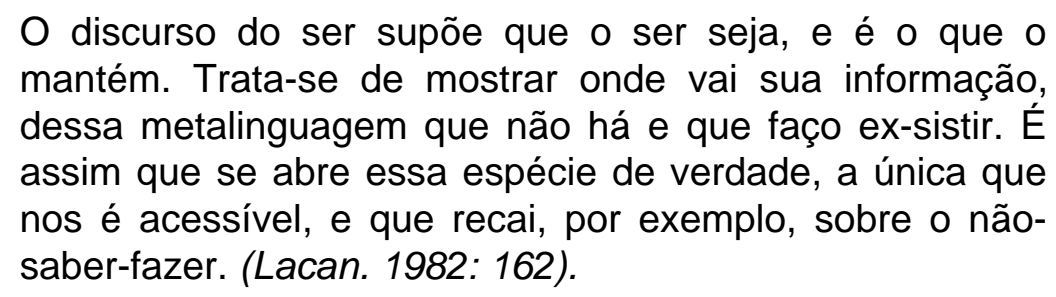

Ou seja, lá onde se coloca uma falsa completude, não há perplexidades nem enigmas. O Ser ou o Real não comparece para romper o circuito do gozo dos sentidos, redimensionando-o. Basicamente, o problema aparece quando é preciso se dar a transferência do conhecimento, dificuldade típica de nossas escolas. 0 silenciamento sobre essa pedra de Sísifo que é a transmissão do conhecimento, o comportamento evasivo em relação às angústias do convívio social e escolar, a alienação intolerante embutida nos valores da instituição em relação a seus membros são recalques institucionais que passam a obstruir a construção da consciência, comprometendo a trama simbólica que apóia o campo psíquico do sujeito diante da manifestação semiótica do mundo e de sua beleza - e abolindo a possibilidade da experiência emocional a ser recebida com algum prazer no interior da mente emergente do indivíduo. Como resultado cria-se um espaço morto, repleto de objetos que são apenas coisas em si (objetos dissociados de seus respectivos sentidos afetivos), sem significado humano, símbolos esvaziados de simbolização.

O que está em questão no desejo é um objeto, não um sujeito. É neste ponto que reside aquilo que se pode chamar de o mandamento espantoso do deus do amor. Esse mandamento é, justamente, de fazer do objeto que ele nos designa algo que, em primeiro lugar, seja um objeto, e, em segundo lugar, um objeto diante do qual 
desfalecemos, vacilamos, desaparecemos como sujeito. Pois essa queda, essa depreciação, nós, como sujeito, é que a sofremos. (Lacan, 1992, p. 172).

Aqui, o espaço entre o desejo e a necessidade está preenchido por essa dúvida em assumir a existência, por essa incerteza, por esse "não quero que despertem o meu desejo", por uma espécie de preguiça letárgica característica das depressões sem sintoma visível - que se opõe a dizer um sim impelido por um desejo, uma necessidade assumida, sem por isso tornar essa luta um peso a ser carregado pelo outro, como se as conseqüências do desejo assumido tivessem de pertencer a outrem.

\section{QUATRO DISCURSOS E UM SINTOMA}

Lacan parte do discurso como a instância que faz vínculo ou liame social. Existem quatro formas possíveis de discursos, ou seja, quatro tipos de relações entre o sujeito e esse espaço tenso com a alteridade, mediadora de todo liame social. $\mathrm{O}$ primeiro é o Discurso do Mestre, que indica a fala daquele que enuncia do lugar do poder. O segundo, o Discurso da Histérica, que, pela divisão que implica a respeito do sujeito, obriga o Mestre a produzir um discurso com semblante de completude e coloca em causa radical a relação poder/saber. Os dois primeiros discursos se tensionam no sentido de que a Histérica está em busca de um Mestre (impossível) que pudesse produzir o saber completo a partir do ponto onde se coloca. O Discurso do Universitário é aquele que de fato se coloca como depositário de um saber, que transmite a cultura, o saber pré-construído capaz até de justificar intelectualmente o poder; ao passo que o Discurso do Analista é aquele de alguém que não tem nada a dizer senão um não-saber e que não "transmite" nada. Este discurso é o discurso da verdade (no sentido daquilo que faz mover o desejo), dado que se fundamenta no inconsciente e faz da psicanálise uma ciência ao inverso, de onde os princípios se fundem a todo o momento.

Dentro da teoria dos quatro discursos, procuramos destacar o Discurso da Histérica, por se enquadrar melhor no caso da citada estagiária do Curso de Letras, mencionado anteriormente. A atitude de seus alunos tende a gravitar e fecham-se no referido discurso sem rodar os matemas, pois os alunos recusaramse a fazer as atividades de produção de fanzines, proposta inicial de criarem livremente o que quisessem, optando por simplesmente rabiscar o papel. Tal atitude, em nossa opinião, está intimamente ligada ao Discurso da Histérica. Segundo Riolfi (1999: 211),

Trata-se do discurso idêntico ao que - mediante condições artificiais - é instituído por uma intervenção do analista durante o desenrolar de uma Psicanálise. Isto porque, colocado para agenciar o discurso está o sujeito na condição daquele que é dividido pelo gozo e que, por sua divisão, não sabe o que diz e muito menos quem o diz, como faz ver Lacan.

Trata-se daquele que não se propõe como ocupando lugar na rede discursiva, oferecendo o não-dizer como um sintoma a decifrar pelo educador no Discurso do 
Mestre. Vale dizer: a recusa do aluno vale como uma tentativa de "furar" a (suposta) completude do mestre, para que seu enigma indecifrável fragilize este último, que desta forma passa a abrir espaço para que a Histérica mantenha esperanças de que seu desejo seja virtualmente (mas jamais de fato) simbolizável.

A autora afirma, ainda (op.cit.: 211-2),

(...) é por esta ignorância fundamental que, durante o decorrer do seu contato com este que suporta a função da transferência, o analista, este não lhe demanda pensamentos coerentes e muito menos organizados e sim que siga a regra da livre-associação, dizendo qualquer coisa que lhe ocorrer.

Em outras palavras, podemos considerar a atitude de os referidos alunos em se negarem a realizar a tarefa proposta como nitidamente situada no lugar da Histérica, tanto quanto pelo fato de terem seguido a regra da livre associação sem se situarem como sujeitos na linguagem, ou seja, no papel, colocando brincadeiras e rabiscos. Dentro dessa natureza discursiva, não há um diálogo entre ambas as partes (professor e aluno), ou seja, não se instaurou a intersubjetividade na relação. Os alunos, nesse caso, optaram por um outro caminho, ou seja, o da negação e o da fuga, ou seja, o Significante-Mestre desaparece do campo do Sujeito para que, em seu lugar, se enuncie o puro sintoma, o silencio. A máscara, a farsa do autoritarismo e as inocuidades da escola levaram os alunos a produzirem seu sintoma. Mas, para que o discurso "gire", e se abandone o Discurso da Histérica em favor da mestria, é preciso que haja, do lado do educador, a predisposição em abrir o espaço para o educando possa se dizer, tornar-se sujeito do seu questionamento. Conforme Lajonquière (1999: 118), a falta de acontecimento da metáfora paterna implica um impasse educativo, ou seja, a impossibilidade de a criança se posicionar no processo de conquista de um lugar no qual Ihe seja possível enunciar singularmente seu desejo.

Dentro do contexto escolar aqui analisado, verifica-se que a professora estagiária teria formado ou criado uma "frustração didático-pedagógica" por ter escolhido um caminho pouco eficaz para se realizar um processo de ensino-aprendizagem. Essa recusa dos alunos em não seguir a proposta de trabalho não pode ser considerada como uma "não-resposta" e sim como uma resposta ao excesso de liberdade que Ihes foi dado (sem o exercício da Lei, o Mestre não se apresenta como tal; sem que haja limites e especificações para a conduta do aluno, este apresenta dificuldades para se posicional nesse papel), impedindo assim que os discursos "girassem" rumo à mestria. Fica claro, portanto, que uma dada tarefa sem uma diretriz pré-determinada com o propósito de orientar uma atividade, coloca o aluno em uma situação de "tudo ou nada", ou seja, quando é dado uma amplitude de trabalho sem direção é ao mesmo tempo um "nada" que se pode esperar: um chamamento ao significante sem significado, um sintoma puro.

\section{PARA ESBOÇAR UMA CONCLUSÃO}


Analisando sob esta óptica, pode-se dizer que o aluno, tendo já implicitamente autorizado o sujeito-professor, espera deste uma mestria inauguradora, o que pode não ter ocorrido por parte da referida estagiária. Houve, sim, uma recusa à mestria, situação diante da qual os alunos se colocaram em posição de sujeitos não-desejantes e preencheram o tempo disponível com atividades tão livres (ou seja, tão esvaziadas de determinação, portanto de sentido) quanto a proposta apresentada.

O professor deve manifestar e administrar a sua mestria, a fim de que possa ocorrer a transferência do conhecimento e que o processo de ensinoaprendizagem se realize, a fim de permitir a emergência de um verdadeiro savoirfaire. Sendo assim, finalizamos lançando uma questão provocativa: que ensino será esse capaz de permitir ao aluno reapropriar-se de sua subjetividade - seu Significante-Mestre, no espaço escolar?

\section{BIBLIOGRAFIA:}

DOR, Joël. Introdução à leitura de Lacan: o inconsciente estruturado como linguagem. Porto Alegre: Artes Médicas, 1989.

ETCHEGOYEN, R. Horacio. Fundamentos da técnica psicanalítica. Porto Alegre: Artes Médicas, 1987.

LACAN, J. O seminário, livro 20. MAIS AINDA. Rio de Janeiro: Jorge Zahar, 1982.

. O seminário, livro VIII: a transferência. Rio de Janeiro: Jorge Zahar, 1992.

LAJONQUIÈRE, Leandro de. Infância e ilusão (Psico) Pedagógica: escritos de psicanálise e educação. Petrópolis: Vozes: 1999.

MRECH, Leny Magalhães. Um sintoma na cultura: a falência da transmissão na relação professor-aluno. URL: www.regra.com.br/educacao/afadatr.htm

REIS, Ayrton R. \& SOUZA. Orion Penna e. "Onde se esconde o desejo de aprender do aluno?" In: Linguagens \& Cidadania, No 5, jan/jun 2001. URL: www.ufsm.br/linguagem_e_cidadania

RIOLFI, Claudia Rosa. O discurso que sustenta a prática pedagógica: formação do professor de língua materna. Campinas: UNICAMP, 1999. Tese de Doutorado. 